\title{
Sharing Knowledge through Sharing Advisor in Age of Sharing Economy: A Conceptual Model
}

\author{
Waqas Khurama, Yanqing Wang ${ }^{\mathrm{b},{ }^{*}}$ \\ School of Management, Harbin Institute of Technology, Harbin 150001, China \\ awaqaskhuram@hit.edu.cn , byanqing@hit.edu.cn \\ ${ }^{*}$ Corresponding author
}

\begin{abstract}
Keywords: sharing economy; advisor sharing; knowledge sharing; need-based theory; coadvisor.net
\end{abstract}

\begin{abstract}
The concept of 'sharing economy' has become a popular concept nowadays. Organizations, irrespective of their nature of business and scope of operations, are now practicing it. Academia has also no exception. The academicians, along with their job of imparting lectures, are now 'sharing the economy' by rendering a broad range of services, such as consultancies, online guiding, research \& development, motivational speaking, editing, report writing and so on to the individuals and business organizations. Online sharing platforms are providing the facilities to interact around the globe and effortlessly access to experts to uphold and get experts opinions. This paper, based on the need-based framework of motivation, introduces a conceptual model that elucidates the entire process underlying the academicians' involvement in the 'sharing economy'. Also, this paper offers certain useful implications for theoretical research.
\end{abstract}

\section{Introduction}

The rapid spread of the Internet and information technology has created a new business model sharing economy. This term has drawn great attention of scholars in short time. It refers to a variety of practices such as sharing of intangibles, bartering and neighborhood initiatives, fee-based rental like services and so on [1]. Also, sharing economy connotes a system in which people, as well as the organizations, share the resources, commodities and even services with others through the means of information technology with the underlying motives of saving money and cost-cutting [1]. The nature of the sharing economy is to integrate online or offline equipment (or services) that enables them to offer products or services at lower prices. Many small, large, national and international organizations today (e.g. Uber, Airbnb, Trivago etc.) are practicing 'sharing economy' by offering their products and services through different platforms. Around 2010, Uber, Airbnb, and some physical sharing platforms started sharing activities based on a purely free sharing, information sharing, to obtaining a certain reward as the main goal. Its form changed from a limited business model "based on strangers and temporary transfer of the right to use goods" to a broader category including knowledge sharing.

Besides their fundamental role of knowledge creation and dissemination, many higher education institutions (HEIs) are now offering different services such as 'consultancy and R\&D services' to industrial and developmental sectors to help facilitate innovation and social development. HEIs are also collaborating with businesses, social and cultural enterprises to facilitate learning and innovation by adopting special teaching, research and training programs for them. Likewise, HEIs are also involved in knowledge management activities. Essentially, the main objective of higher education institutions is to create, preserve, integrate, disseminate and apply knowledge. Among these, knowledge sharing is claimed to be the most important part of knowledge management [2] and may be referred as to the set of individual behaviors that allow someone to share their work-related knowledge and experience with organizational members so that the absolute of 'effectiveness' may be achieved [1]. However, in the context of higher educational institutions, knowledge sharing behavior refers to the sharing of work-related knowledge and other expertise by the faculty members with their fellow colleagues within the university. However, unfortunately, researchers report a comparatively weaker desire or willingness of knowledge sharing for the sake of achieving common 
objectives in the universities [3]. Since the willingness to share knowledge is one of the prerequisites for knowledge management [4]; hence, understanding what motivates individuals to share their knowledge and expertise with their colleagues becomes imperative.

Prior research provides useful insights into the factors that might influence knowledge sharing [5-6], yet little known about what motivates academicians to share their knowledge. Therefore, this paper, by introducing a conceptual framework based on the motivational framework [7], seeks to answer this very important question.

\section{Theoretical background}

Sharing as an activity is as ancient as the humanity itself [8] and exists in our societies since the existence of humans in this universe. Literally, sharing refers to the joint use of any either resource, tangible (goods) or intangible (services) [9]. In comparison to its alternative modes, sharing helps foster the community, conserve resources and create certain collaborations. By sharing, one can enjoy certain benefits such as reduced burden of expenses or losses. Generally, the concept of sharing is confined to the exchange of 'tangible goods', however, the objects of abstract nature (e.g. knowledge, ideas, values, time and responsibility or authority) may also be shared. In case of knowledge sharing, the parties involved have to share both the cost and benefits associated with the object being shared, which are considered to be the most important antecedents of knowledge sharing. Social exchange theory also suggests evaluating the perceived ratio of benefits to costs and taking decisions or actions based on the expectation that it will lead to certain rewards such as respect, reputation, or the tangible incentives.

(1) Sharing Economy. Sharing economy is a unique concept. A number of terms are used to represent the core of 'sharing economy' [10] such as 'pseudo sharing' [8], 'commercial sharing system' [11]. A sharing economy is a socioeconomic approach based on sharing living or non-living resources. It is pointed out that the very term places a great emphasis on the social relationships and neglects the core of what they call the access economy - low-cost and convenient consumption of anything [12]. The concept of sharing economy has certain features, which are different from other common businesses trades. These features include "non-ownership, temporary access, and distribution of goods or less tangible assets such as money, space, or time and knowledge" [13]. In sharing economy system, the relationship with the participant can be private or public, depending on the participant concerns and activities in such systems [12]. The advent of P2P platforms, collectively known as the 'sharing economy', has allowed people to perform collective activities and make use of listed activities through fee-based sharing.

(2) Knowledge Sharing. Knowledge is becoming a main resource for all organizations, which allowing individuals to take decisions on the basis of such knowledge sharing. The newer and latest knowledge that any society, community or the organization has, the more advantageous they will be. Well-established organizations acquire the newest information \& knowledge through the knowledge and skillsets of their staff, because knowledge being a resource, allows people to convert information into decisions and actions. Knowledge sharing is a process where an individual willfully shares the knowledge with others [12]. Knowledge sharing is thus a voluntary act, although the mail goal of knowledge sharing is to transfer knowledge that one has to others within an organization [5]. The sharing of knowledge among individuals is the process by which an individual transfers his /her knowledge of expertise in a way which can be understood and accepted by the receiver.

(3) Knowledge Sharing Through Advisor. Knowledge sharing is a set of individual behaviors involving the sharing of knowledge and practical experience that deemed pertinent to the organizational members and organization itself, with the aim of enhancing the overall effectiveness of the organization [3]. Knowledge-based organizations like HEI's are essential platforms for the students- teachers and faculty-faculty interactions for sharing of knowledge i.e. expertise, research invention is shared most frequently manner, which inspire the young scientist and scholars. In HEIs, the knowledge sharing behavior of academicians refers to the way the faculty members share their knowledge and work experience with fellow faculty members and students within the university to uplift the overall standard of the university. Higher education Institutions are the platforms for the 
student-teacher interactions, where knowledge is created and shared through cutting-edge research and various pedagogical approaches. Academicians in HEIs are therefore playing a pivotal role as knowledge creators and providers via teaching, seminars, conferences and continuous research programs. As researchers, academicians in HEIs, along with their own research, also supervise the research of their students. Such individuals, who also known as advisors, are self-motivated and well-trained specialists who lead and guide students in their respective areas of research through sharing their knowledge, expertise and relevant experience, by doing so, the advisors or the supervisors play a significant role in the professional development of their advisees. Their prime responsibility is to share knowledge to help facilitate collective learning [5]. Thus, an advisor should be motivated and desirous of sharing their own achievements, expertise, discoveries, creative theories and critical interpretations with their fellow colleagues and students in particular field.

(4) Motivation to Share Knowledge. The term motivation is often explained as a psychological process that drives inner force of individuals into actions [6]. According to a literature [5], motivation is one of the main driving forces that influence one's decision to share his/her knowledge. Because knowledge is "closely associated with the person's professional ego" [12]. In addition, without the willingness of individuals, it is quite difficult to access their knowledge. A study states that individuals are unlikely to share their knowledge without solid personal motivation [10]. It has also been observed that an individual may prefer to hold his/her knowledge until some motivational elements push them to do so. Effective knowledge exchange practices, therefore, depend on the willingness of individuals. More specifically, the motivation of an individual can influence his/her behavior towards knowledge sharing and productivity within the workplaces [13]. Primarily, for successful knowledge sharing, organizations heavily dependent upon the willingness of their members to participate in knowledge sharing activities. Also, researchers also opine that the deficiency of motivation can adversely affect knowledge sharing behavior [13]. Some of the factors that could positively influence one's intention and willingness to share knowledge are the personal benefits and the social concerns [14]. Hence, the intrinsic and extrinsic motivational factors are the essential ingredients of intentions to share [13].

\section{Model development}

The motivational theories, based on their underlying perspectives, are generally classified into two broad categories: the content theories and the process theories [14-16]. The first category captures the motivational factors while the latter discusses the approaches and processes by which motivation takes place [14]. Among these, the need-based motivational framework proposed by [7], is worth discussing as it underpins our conceptual model (see Fig. 1).

According to this framework, motivation stems from the 'need' that may be defined in terms of motives, desires or purposes. A need or a deficiency triggers individual actions to search for the ways to satisfy it. [15] stresses that the desire to fulfill these needs may come in any order, therefore after finding the ways, the next step could be the choice of the behavior via which he/she can satisfy his/her need. Individuals always have an alternative option to carry out and select the most appropriate behavior which as per the individual's perceptions, may lead him/her towards inner satisfaction. After selecting a course of action of behavior, the individual then evaluates the extent of his /her need satisfaction, which then determines his/her future behavior.

As discussed earlier that need is the starting point for any individual's motivation, and that it stimulates their thoughts and actions, hence it can be rightly asserted that motivation depends upon satisfying the needs [16]. Despite the fact that a dissatisfied need is a good motivator, a satisfied need can also motivate individuals to achieve more and more, but the unsatisfied need is usually deeper. The need could be anything intrinsic or extrinsic [16]. Intrinsic motivation could also take the form of knowledge sharing for innate satisfaction, whereas the extrinsic motivation involves tangible and intangible rewards resulting from knowledge sharing [6]. Physical rewards of knowledge sharing could be the monetary and non-monetary benefits [17]. Research also elucidates that extrinsic motivations positively influence an individual's willingness to share knowledge [18]. An advisor's motivation towards knowledge sharing may also be viewed from the needs perspectives and it may be 
assumed that the monetary (money) and non-monetary benefits motivate advisors to share their knowledge.

Having said that needs underlie an advisor's knowledge sharing; these needs would then determine the ways via which an advisor may satisfy his/her need. The possible ways through which advisors may satisfy their needs could include face-to-face meetings, telecommuting, lecture sessions, social networking sites, blogging or virtual networks. Advisors, by realizing their needs, may opt one of these. However, researchers, in the recent years have observed and reported the fast-growing trend of knowledge sharing through knowledge networks [19]. Additionally, internet-facilitated sharing systems are also in vogue [20]. However, despite an increasing trend of using information technology as a means of knowledge sharing, face-to-face or direct interactions still stand important [21]. Because, face-to-face meetings provide many opportunities concerning the creation, sharing, and utilization of knowledge [22]. Despite the usefulness of both, the face-to-face and internet-mediated knowledge sharing methods, the choice of methods would mainly remain in the hands of an advisor. However, the role of knowledge seekers cannot be ignored, as his/her, preferences would matter especially when he/she is willing to pay. Hence, the next step, as per our base model would be the evaluation and selection of an appropriate knowledge sharing method. One selected, the advisor will execute it. The whole execution process may stretch a little long. As, the process of knowledge creation (e.g. R\&D, report writing, analysis and preparing reports etc.) consumes time. After execution phase, advisors will evaluate their performance so as to determine the extent of their need satisfaction which would then determine their future goals or behaviors. During this process, several factors, including most importantly 'one's emotions', would matter [23]. In their study, they evaluated the influence of emotional factors, also called emotional engagement, on the knowledge sharing behavior and found that affective commitment and affective trust towards academics' knowledge sharing behavior. Some very obvious factors such as the intrinsic and extrinsic rewards, the reciprocal relationship, and sense of self-worth, fairness, affiliation, and innovation also matter [24]. Based on above discussion and the theoretical underpinnings, the following model is proposed, as shown in Fig. 2.

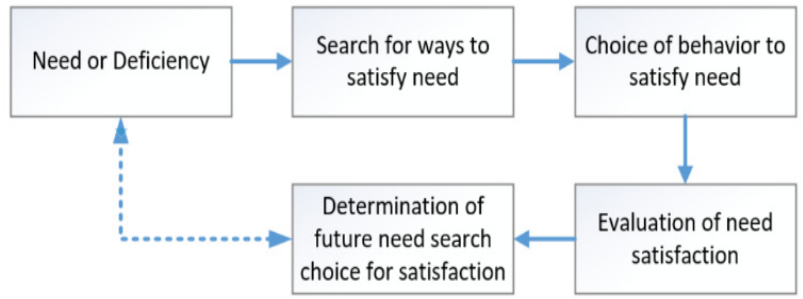

Fig. 1. Motivational framework

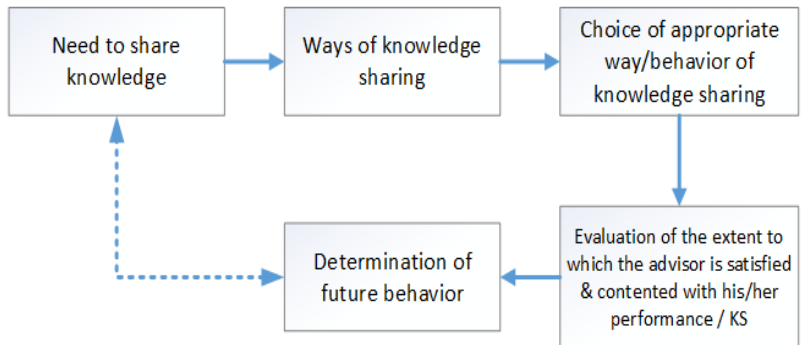

Fig. 2. The conceptual model of knowledge sharing

\section{Conclusion}

Since the pivotal aim of this article was to explore the factors that could motivate an advisor's knowledge sharing behavior in HEIs, online platforms and to identify the process via which the whole motivation takes place, therefore a conceptual model is proposed. The demand for online teaching and learning programs is growing day by day because of the growing number of online programs, especially at the postgraduate level. Continuous development in pedagogical pattern has opened the door for creation of online learning communities for the access and interactions of learners. Internet-based online virtual learning platforms has created the opportunities for learners and advisor to share their expertise and to uphold someone problem in the very field. Such technological platform gives an opportunity to get economic benefits by sharing their ideas and participate in sharing economy through such information systems platforms. Different empirical studies are required to validate this model and platform and also see the impact of such platform on individuals' behavior while sharing or receiving. Future researchers may also base their indigenous research on the philosophy underlying this model. 


\section{Acknowledgments}

This research was financially supported by the National Natural Science Foundation of China (Grant NO. 71573065 and Grant NO. 71571085).

\section{References}

[1] M. P. Wilhelms, K. Merfeld, and S. Henkel, Yours, mine, and ours: A user-centric analysis of opportunities and challenges in peer-to-peer asset sharing, Business Horizons, vol. 60, no. 6, pp. 771-781, 2017.

[2] G. W. Bock, R. W. Zmud, Y. G. Kim, and J. N. Lee, Behavioral Intention formation in knowledge sharing: Examining the roles of extrinsic motivators, social-psychological forces, and organizational climate, MIS Quarterly, vol. 29, no.1, pp. 87-111, 2005.

[3] H. Kong, A study on the university professor's intention of knowledge-sharing. Kwangju, South Korea: Jun Nam University Kwangju, 1999.

[4] C. N. L. Tan and S. Md. Noor, Knowledge management enablers, knowledge sharing, and research collaboration: A study of knowledge management at research universities in Malaysia, Asian Journal of Technology Innovation, vol. 21, no. 2, pp. 251-276, 2013.

[5] M. Ipe, Knowledge sharing in Organizations: A conceptual framework, Human Resource Development, vol. 2, pp. 337-359, 2003.

[6] W. Khuram, A. Bhutto, and A. Jabeen, Analyzing the Impact of Higher Education Commission Policies on Motivation of the Faculty Member of Jamshoro Education City, International Journal of Academic Research in Business and Social Sciences, vol. 7, no. 6, pp. 232-257, 2017.

[7] R.W. Griffin, Fundamentals of management. Cengage Learning, 2016.

[8] R. Belk, Sharing versus pseudo-sharing in Web 2.0, Anthropologist, vol. 18, pp. 7-23, 2014.

[9] V. Milanova and P. Maas, Sharing intangibles: Uncovering individual motives for engagement in a sharing service setting, Journal of Business Research, vol. 75, pp. 159-171, 2017.

[10]C. J. Martin, The sharing economy: A pathway to sustainability or a nightmarish form of neoliberal capitalism? Ecological Economics, vol. 121, pp. 149-159, 2016.

[11]C. Lamberton and R. L. Rose, When is ours better than mine? A framework for understanding and altering participation in commercial sharing systems, Journal of Marketing, vol. 76, pp. 109-125, 2012.

[12] G. M. Eckhardt and F. Bardhi, The sharing economy is not about sharing at all, Harvard Business Review, January 28, 2015.

[13]W. Kathan, K. Matzlerm, and V. Veider, The sharing economy: your business model's friend or foe? Business Horizons, vol. 59, no. 6, pp. 663-672, 2016.

[14]M. Osterloh and B. S. Frey, Motivation, knowledge transfer, and organizational forms, Management Review, vol. 42, no. 5, pp. 71-80, 2000.

[15]A. Ardichvili, Learning and knowledge sharing in virtual communities of practice: motivators, barriers, and enablers, Advances in Developing Human Resources, vol. 10, no. 4, pp. 514-554, 2008.

[16]M. S. Rahman, N. M. Daud, and H. Hassan, Generation "X" and "Y" knowledge sharing behavior: The influence of motivation and intention on the non-academic staff of higher learning institutions, Journal of Applied Research in Higher Education, vol. 9, no. 2, pp. 325-342, 2017.

[17]P. Akhavan, R. Akbar, and M. Gholamhossein, Developing a model for knowledge sharing in research centers, VINE, vol. 43, no. 3, pp. 357-393, 2013. 
[18]A. H. Maslow, Towards a Psychology of Being, Van Nostrand, New York, 1968.

[19]C. P. Alderfer, Human Needs in Organizational Settings, Free Press, New York, 1972.

[20]D. C. McClelland, Human Motivation, Cambridge University Press, Cambridge, 1987.

[21]M. Gagne, A model of knowledge-sharing motivation, Human Resource Management, vol. 48, no. 4, pp. 571-589, 2009.

[22]E. L. Deci and R. M. Ryan, The "what" and "why" of goal pursuits: Human needs and the self-determination of behavior, Psychological Inquiry, vol. 11, no. 4, pp. 227-268, 2000.

[23]J. Lou, Y. Fang, K. H. Lim, and J. Z. Peng, Contributing high quantity and quality knowledge to online Q\&A communities, Journal of the Association for Information Science \& Technology, vol. 64, no. 2, pp. 356-371, 2013.

[24]M.-Y. Cheng, J. S.-Y. Ho, and P. M. Lau, Knowledge sharing in academic institutions: A study of Multimedia University Malaysia, Electronic Journal of Knowledge Management, vol. 7, pp. 313-324, 2009. 